\title{
Gastronomia e Turismo: Reflexões Sobre a Preservação da Culinária Tradicional na Cidade de Caldas Novas (Go)
}

\author{
Gastronomía y Turismo: Reflexiones Sobre la Preservación de la \\ Culinaria Tradicional en la Ciudad de Caldas Novas (Go)
}

\section{Adriana Roveri das Neves ${ }^{1}$ André Luiz Caes ${ }^{2}$}

\begin{abstract}
Resumo
A cidade de Caldas Novas, polo turístico encravado no interior do estado de Goiás e com importância econômica crescente, não só regional como nacional, é o ponto de partida para o objetivo de refletir sobre a importância da história e da cultura regionais para uma renovada percepção do turismo em todas as suas vertentes. Apesar de faltarem dados científicos sobre tal afirmação, sabe-se que os locais onde há recuperação e preservação histórica são os mais visitados em escala internacional, não só em termos de patrimônios visíveis ou materiais (arquitetura, arte, vestuário etc.), mas também outras características inerentes à cultura, como as festas, a dança e a gastronomia, que constituem, em sua composição, o patrimônio intangível de uma sociedade ou destino turístico. Neste sentido, incita-se a preservação do patrimônio cultural em um local de atração turística como um fator de contribuição para o desenvolvimento local em uma perspectiva sustentável. Para que isto ocorra, é necessário que a população local se envolva com este patrimônio histórico, consolidando o valor e o sentido histórico e até mesmo emocional deste para esta população. Há no turismo, e no desenvolvimento do mesmo, uma necessidade cada vez mais premente de se estudar e caracterizar não só os impactos econômicos envolvidos, mas também os impactos ambientais, sociais, psicológicos, geográficos, antropológicos e históricos, apesar do enfoque financeiro ainda ser em grande parte o norteador dos demais estudos. Nesta perspectiva, desenvolveu-se este artigo buscando refletir sobre a possibilidade de reencontrar a identidade histórico-cultural a partir das receitas que caracterizam este polo turístico nacional que é Caldas Novas, tendo como objetivos não apenas compreender a importância da preservação do patrimônio cultural imaterial para o desenvolvimento do turismo, mas também deste como mediador da recuperação e preservação do patrimônio cultural de uma localidade.
\end{abstract}

Palavras-Chave: Caldas Novas (GO); Culinária; Patrimônio Cultural Intangível; Sustentabilidade.

\section{Resumen}

La ciudad de Caldas Novas, por el turístico enclavado en el interior del estado de Goiás y con una importancia económica creciente, no sólo regional como nacional, es el punto de partida para el objetivo de reflexionar sobre la importancia de la historia y la cultura regionales para una renovada percepción del turismo en todas sus vertientes. A pesar de faltar datos científicos sobre tal afirmación, se sabe que los lugares donde hay recuperación y preservación histórica son los más visitados a escala internacional, no sólo en términos de patrimonios visibles o materiales (arquitectura, arte, vestuario, etc.), sino también otras características inherentes a la cultura, como las fiestas, la danza y la gastronomía, que constituyen, en su composición, el patrimonio intangible de una sociedad o destino turístico. En este sentido, se incita la preservación del patrimonio cultural en un lugar de atracción turística como un factor de contribución al desarrollo local desde una perspectiva sostenible. Para que esto ocurra, es necesario que la población local se involucra con este patrimonio histórico, consolidando el valor y el sentido histórico e incluso emocional de éste para esta población. En el turismo, y en el desarrollo del mismo, una necesidad cada vez más urgente de estudiar y caracterizar no sólo los impactos económicos implicados, sino también los impactos ambientales, sociales, psicológicos, geográficos, antropológicos e históricos, a pesar del enfoque financiero todavía en gran parte el orientador de los demás estudios. En esta perspectiva, se desarrolló este artículo buscando reflexionar sobre la posibilidad de reencontrar la identidad histórico-cultural a partir de los ingresos que caracterizan este polo turístico nacional que es Caldas Novas, teniendo como objetivos no sólo comprender la importancia de la preservación del patrimonio cultural inmaterial para el desarrollo del turismo, pero también de éste como mediador de la recuperación y preservación del patrimonio cultural de una localidad.

Palabras claves: Caldas Novas (GO); Cocina; Patrimonio Cultural Intangible; Sostenibilidad.

\section{Abstract}

The city of Caldas Novas, a tourist attraction located in the interior of the state of Goiás and of growing economic importance, not only regional but also national, is the starting point for the purpose of reflecting on the 
importance of regional history and culture for a renewed perception of tourism in all its aspects. Although there is a lack of scientific data on this, it is known that the places where there is historical recovery and preservation are the most visited on an international scale, not only in terms of visible or material heritage (architecture, art, clothing, etc.), but also other characteristics inherent to culture, such as festivals, dance and gastronomy, which constitute, in its composition, the intangible heritage of a society or tourist destination. In this sense, the preservation of cultural heritage is encouraged in a place of tourist attraction as a contribution factor for local development in a sustainable perspective. For this to happen, it is necessary that the local population get involved with this historical patrimony, consolidating the value and the historical and even emotional sense of this for this population. There is, in tourism and in the development of tourism, an ever more pressing need to study and characterize not only the economic impacts involved but also the environmental, social, psychological, geographic, anthropological and historical impacts, in large part the guide of the other studies. In this perspective, this article was developed in order to reflect on the possibility of rediscovering the historicalcultural identity from the recipes that characterize this national tourist pole that is Caldas Novas, whose objectives are not only to understand the importance of the preservation of intangible cultural heritage for the development of tourism, but also as a mediator of the recovery and preservation of the cultural heritage of a locality.

Key words: Caldas Novas (GO); Cooking; Intangible Cultural Heritage; Sustainability.

\section{Introdução}

Caldas Novas, polo turístico do interior do Estado de Goiás reconhecida como "a maior estância hidrotermal do mundo", é objeto de estudo para a proposição de um desafio de discussão sobre a importância da história e da cultura regionais para o incentivo ao turismo em todas as suas vertentes. Conforme cita Schlüter (2003), apesar de faltarem dados científicos sobre tal afirmação, sabe-se que os locais onde há recuperação e preservação histórica são os mais visitados em nível internacional, não só em termos de patrimônios visíveis ou materiais (arquitetura, arte, vestuário etc.), mas também outras características inerentes à cultura, como as festas, a dança e a gastronomia, que constituem, em sua composição, o patrimônio intangível de uma sociedade ou destino turístico.

Dentre os bens culturais que estão sendo objeto de estudos para preservação, escolheuse refletir sobre a gastronomia ou culinária típica de Caldas Novas, bem cultural que está se perdendo dentro do contexto de consolidação dessa cidade como um dos principais locais turísticos de Goiás e do Brasil. Nessa perspectiva, acompanhamos o pensamento de Nardin (2015, p. 13), que propõe:

$\mathrm{O}$ ato de comer se torna então um verdadeiro discurso do passado e o relato nostálgico do país, da região, da cidade ou do lugar em que nasceu. Evidente, então, que o ato de comer pode expressar as memórias e características de um povo. A memória tida como tudo aquilo que lembra uma cultura, um passado em comum.

Num sentido amplo, falar de gastronomia é falar de como nos tornamos humanos e evoluímos ao que somos hoje. De acordo com Braune e Franco (2006, p. 18) "a cocção dos alimentos os tornaria mais fáceis de mastigar”. Biologicamente falando, significa dizer que, como não houve mais a necessidade de se desenvolver a musculatura da face e a arcada dentária para o esforço da mastigação, aumentou o espaço na caixa craniana para o 
desenvolvimento do cérebro. Ainda conforme Braune e Franco (2006, p. 23), "a tendência humana de compartilhar alimento, ideia básica da hospitalidade, teria se originado quando o homem desenvolveu a capacidade de matar grandes presas". Ou seja, o compartilhar das refeições criou no ser humano a vontade de receber, hospedar, convidar a participar de seu local de residência ou convívio social, que são as bases do surgimento do turismo no mundo.

Este estudo pretende refletir sobre o processo de revitalização da cultura gastronômica local dentro do conjunto das atividades turísticas, propondo que esta seja valorizada como um dos elementos de atração dos turistas em suas diversas vertentes (lazer, saúde, negócios etc.). Dessa forma, é possível agregar os valores culturais e históricos aos diversos ramos do turismo na cidade de Caldas Novas-GO. Conforme cita Dias (2006), usar a cultura (material ou imaterial) de um local para fins econômicos pode ampliar o acesso desta população a uma melhor qualidade de vida.

\section{A Gastronomia como inflexão reflexiva da sociedade}

A Gastronomia sempre consistiu num elemento fundamental das sociedades humanas. Pode-se afirmar que os alimentos e sua forma de preparo participam da história humana desde o início, primeiramente e, talvez, durante longo tempo, sendo valorizados pelo simples fato de garantir a sobrevivência, depois escolhidos a partir da possibilidade de conseguir excedentes para a manutenção de comunidades maiores, e ainda depois como recurso fundamental para a formação de aglomerados urbanos e sustento de grandes populações, sendo ao mesmo tempo fundamento da força política, econômica e comercial das sociedades já estatais.

Nessa longa história da Gastronomia, chegou-se à construção, em todas as culturas, de culinárias tradicionais que expressam diferentes elementos da cultura local, regional ou de um povo ou país. Esses elementos podem ser conhecidos e estudados de forma científica, sendo valorizados hoje por tudo aquilo que podem nos dizer sobre a história da alimentação humana e sua diversidade de manifestações. Nessa perspectiva, Müller (2012, p. 23) propõe:

A tradição, o valor simbólico dos alimentos, a história, os sabores e saberes, as técnicas de produção e os modos alimentares são responsáveis pela formação de culturas gastronômicas regionais. Esses valores intangíveis somados constituem os chamados Patrimônios Culturais de Natureza Imaterial. Os significados da alimentação para as sociedades não podem ser mais compreendidos dentro de uma epistemologia que abrange somente indicadores econômicos, nutricionais e biológicos.

A partir do ano de 2003, quando a UNESCO estabeleceu a "Convenção para a Salvaguarda do Patrimônio Imaterial", não apenas a Gastronomia, mas todas as demais expressões da cultura imaterial passaram a receber um olhar de renovado interesse. Nessa perspectiva os patrimônios imateriais foram definidos como: 
[...] práticas, representações, expressões, conhecimentos e técnicas - junto com os instrumentos, objetos, artefatos e lugares culturais que lhes são associados - que as comunidades, os grupos e, em alguns casos, os indivíduos reconhecem como parte integrante de seu patrimônio cultural. (UNESCO - Convenção para a Salvaguarda do Patrimônio Imaterial, 2003, p. 1)

A preocupação pela preservação desses patrimônios aconteceu, sobretudo, pelo fato de a globalização estar provocando o desaparecimento de inúmeras formas de expressão cultural pelo mundo, de forma mais grave no campo das linguagens tribais ou étnicas, mas também no de outras manifestações culturais como a alimentação. No campo da Gastronomia essa preocupação também é bastante pertinente, conforme propõem Müller, Amaral e Remor (2010):

\begin{abstract}
Observa-se atualmente que as preparações das cozinhas típicas vêm perdendo certas características histórico-culturais, uma vez que a memória coletiva e o conhecimento oriundo do processo de elaboração destas preparações tradicionais estão desaparecendo, por conta da mundialização dos mercados, da homogeneização das cozinhas, de uma alimentação mais barata ou mais rápida e pela facilidade de aquisição de novas mercadorias estranhas a cultura de origem.
\end{abstract}

Assim, nas pesquisas e propostas atuais de preservação e valorização dos saberes gastronômicos tradicionais, existe uma preocupação em constituir não apenas um acervo de conhecimentos sobre essas manifestações culinárias locais, regionais ou nacionais, mas também com a perspectiva de que esse patrimônio imaterial seja compreendido como um bem cultural que pode se constituir em bem econômico, principalmente quando associado às atividades turísticas que hoje movimentam um extraordinário mercado em todo o mundo.

É nesse sentido que Müller, Amaral e Remor (2010), a partir do trabalho de Flandrin e Montanari (1996), entendem que "as cozinhas de comidas típicas são elementos da cultura regional, de perpetuação da memória culinária das famílias e podem oferecer ganhos de recursos econômicos, tanto para a indústria como para o comércio local".

Tendo em vista essas possibilidades apresentadas pelos estudos até agora realizados sobre a Gastronomia tradicional ou típica, estimulados pela perspectiva de preservação do patrimônio cultural imaterial e pela oportunidade econômica que se abre com o aproveitamento desse patrimônio integrado às atividades turísticas, este presente trabalho procura lançar o olhar sobre a situação atual da culinária típica de Caldas Novas (GO), com o intuito não apenas de refletir sobre formas de preservar esse patrimônio, mas também de transformar a atividade turística e a cultural local pela valorização dessa tradição.

\title{
3. A ameaça da perda do Patrimônio Histórico Gastronômico de Caldas Novas
}


Caldas Novas constitui um interessante objeto de estudo, não apenas por ter sua economia voltada para o turismo, mas especialmente porque esta atividade econômica se desenvolveu de maneira quase irresponsável e sem planejamento específico para a diversidade de questões que estão envolvidas na expansão econômica das regiões com potencial turístico.

As ações empreendidas no turismo de Caldas Novas foram favorecidas por sua localização e seu produto - as águas termais - enfocando quase que exclusivamente o turismo de lazer, sendo que este desenvolvimento gerou impactos ambientais, culturais e sociais. $\mathrm{O}$ rápido crescimento populacional, que ocorreu de maneira desordenada, está levando à degradação do meio físico, de forma mais grave na sua área urbana, o que já tem afetado a sustentabilidade ambiental, mas também nas áreas naturais ao redor da cidade.

As reflexões obtidas pelas leituras de Siqueira (2012), Oliveira (2001), Paulo (2005) e os dados obtidos do censo do IBGE (2010) nos levam a afirmar que, no seu aspecto social, a cidade de Caldas Novas possui basicamente todos os problemas das cidades do Centro-Oeste e do Brasil em geral: a cidade e região se confrontam com problemas de baixos salários, a falta de mão de obra qualificada, sazonalidade econômica e problemas com saneamento básico. Com o turismo crescendo de modo desordenado, sem estratégia para desenvolvimento equilibrado, acabou ocorrendo por um lado o crescimento hoteleiro ilimitado e por outro o aumento das carências municipais em equipamentos culturais, lazer, infraestrutura de suporte como, por exemplo, serviço de água e esgoto.

Caldas Novas possui apenas o Plano Diretor Urbano, que contém propostas de organização do crescimento da cidade. Porém, não possui nenhum planejamento relacionado ao turismo, o que dificulta o desenvolvimento turístico da cidade e a sobrevivência das empresas ligadas ao setor. A cidade possui sinalização turística, apesar de em certas áreas ser insuficiente. Por medidas emergenciais de implementação, as placas não possuem continuidade, na região central indicam como chegar ao ponto turístico, mas ao afastar-se desse setor, elas se tornam escassas ou inexistentes.

O desenvolvimento da hotelaria está sendo dificultado pelo fato de condomínios, vendidos como residenciais, estarem sendo comercializados como flats. Como os condomínios residenciais pagam impostos mais baratos que os comerciais, oferecem diárias bem mais baratas, na maior parte possuem área de lazer, porém não oferecem todos os serviços de hotéis. Devido à ausência de um plano de desenvolvimento turístico, a hotelaria vem sofrendo problemas devido ao crescimento desenfreado na oferta de leitos. Com isso, pequenos hotéis estão desaparecendo, pois não conseguem competir com a concorrência. 
Para se construir a imagem de uma localidade turística leva-se tempo e investimento. Mesmo o turismo dependendo da população para a boa divulgação do potencial turístico do local, Caldas Novas não possui nenhuma campanha de conscientização da população local quanto a esta importância, apesar das recomendações amplamente divulgadas pelos órgãos fomentadores do turismo em nível nacional e mundial quanto à essa necessidade. A criação do slogan "A maior estância termal do mundo" favorece a divulgação do destino, por provocar curiosidade e impacto, causando uma boa imagem quando associada a símbolos visuais.

Mesmo com o empenho empreendido atualmente pelos órgãos públicos e empresas privadas para divulgar Caldas Novas, alguns atrativos turísticos não são divulgados e/ou desenvolvidos no município, como o desenvolvimento do turismo saúde, com ênfase nas propriedades das águas termais. Outros atrativos que poderiam ser apresentados e que fortaleceriam a oferta de opções seriam a recuperação das características locais da culinária caldas-novense e sua valorização no interior do circuito gastronômico. As riquezas da fauna e flora locais trazem nuances específicas para a execução dos pratos, mesmo que pautadas em uma tradição maior da culinária típica regional, além das tradições e necessidades que os colonizadores do município enxergaram ao fixarem raízes aqui.

Segundo o Decreto 3.551/2000 (IPHAN, 2000), o patrimônio imaterial cultural brasileiro compreende os saberes, os ofícios, as festas, os rituais, as expressões artísticas e lúdicas que, integrados à vida dos diferentes grupos sociais, configuram-se como referências identitárias na visão dos próprios grupos que as praticam.

Quando se diz que "as formas de expressão e os modos de criar, fazer e viver" (BRASIL, 1988) são bens culturais, pode-se inferir que compartilhar um modo de preparar uma comida, uma forma de consumi-la e os rituais que envolvem a comensalidade de uma sociedade são também seu patrimônio. Considerando que patrimônio faz referência, também, ao dia-a-dia, a culinária se valida como bem cultural. Neste contexto, a gastronomia é meio de caracterização, considerando que a identidade cultural é comunicada às pessoas também por meio da comida.

De acordo com Machado; Braga (2010), o vínculo entre alimentação e patrimônio cultural firmou-se através de ações do IPHAN, que registrou como bem cultural os modos de fazer de algumas comidas típicas brasileiras, como por exemplo, o registro do Ofício das Baianas de Acarajé, em 2005; o Modo artesanal de fazer o Queijo de Minas, nas regiões do Serro e das Serras da Canastra e do Salitre, em 2008; a Produção Tradicional e Práticas Socioculturais Associadas à Cajuína no Piauí, em 2014. Esses registros de práticas culinárias 
únicas reforçam a importância dos aspectos regionais na constituição de uma identidade nacional. Trata-se de reconhecer elementos culturais, étnicos e religiosos que identificam um povo e um local.

A Organização Mundial do Turismo - OMT - define o turismo sustentável como sendo aquele "que atende às necessidades dos turistas atuais e das populações das regiões anfitriãs, ao mesmo tempo em que protege e amplia as oportunidades para o futuro" (MACHADO; BRAGA, 2010). Isso significa que os recursos devem ser geridos de tal forma que as atuais necessidades econômicas, sociais e harmônicas possam ser satisfeitas mantendose, para o presente e para as gerações futuras, a integridade cultural, os processos biológicos essenciais, a diversidade biológica e das formas de vida.

Conforme apreende-se das leituras de Machado; Braga (2010) e Pelegrini (2016), o turismo, atualmente, tem sido exercido por pessoas que, de forma geral, são mais bem informadas do que a média, interessadas na história do local e da região, interessadas nas manifestações do patrimônio imaterial. Muitos podem ir além e se interessar até mesmo por associar mais possibilidades de conhecimento e formação à sua viagem. Dessa forma, são muito bem recebidas as iniciativas de cursos sobre temas direta ou indiretamente vinculados ao local visitado, como música, artes, arquitetura, patrimônio, culinária etc. A ausência de atividades culturais e de lazer repercute negativamente no tempo de permanência dos turistas e, portanto, no seu consumo de bens e serviços, que será mais elevado se a cidade oferecer uma agenda cultural de qualidade.

Muitas vezes, bens reconhecidos como patrimônio imaterial têm também significação econômica para as comunidades que os mantêm. A produção artesanal, por exemplo, além de seu valor cultural e do seu potencial de fortalecimento da coesão entre grupos sociais, é alternativa de renda para muitas comunidades. Na sua relação com o turismo, é necessário cuidar sobretudo das condições de transmissão dos conhecimentos entre gerações e de apoio à produção e distribuição desses bens. (MACHADO, 2010)

Hugues de Varine (2012) argumenta que o patrimônio cultural deve ser abordado da perspectiva de três fatores básicos: o fator conhecimento, o fator bens culturais e o fator meio ambiente. Sob essa vertente, define o "patrimônio do conhecimento" como os "costumes", as "crenças" e o "saber fazer" capaz de viabilizar a sobrevivência do homem no meio ambiente onde vive, e delimita o "patrimônio dos bens culturais" como conjunto de artefatos e tudo o mais que deriva do uso do patrimônio ambiental. Este último contempla os elementos inerentes à natureza, como o próprio meio e os recursos naturais. 
Conforme nos noticia Pelegrini (2006), nas últimas décadas do século XX, a conceituação de patrimônio se ampliou, não se limitando à definição de sítios arqueológicos, obras de arte, monumentos, conjuntos arquitetônicos ou antigos objetos referentes às representações do poder político e social. Essa noção estendeu-se aos diversos modos de viver, formas de linguagem, celebrações, festas, gastronomia, enfim, maneiras de usar os bens, os espaços físicos e a paisagem. A ascensão dos bens simbólicos à condição de patrimônio estimulou a sociedade - em especial, as minorias e os grupos étnicos - a reivindicar o reconhecimento multifacetado de seus referenciais culturais e identificadores.

Desta forma, a perspectiva integradora das políticas em defesa do meio ambiente, do patrimônio cultural e do incremento de atividades turísticas tem resultado em experiências positivas no sentido da promoção da cidadania e do desenvolvimento sustentável. As cartas patrimoniais - documentos elaborados por especialistas e órgãos ligados à preservação patrimonial com o intuito de delimitar conceitos, normativas, ações e metodologias para a conservação, manutenção e restauração de um patrimônio histórico, artístico e cultural (IPHAN, 2015) - dedicadas ao assunto reafirmam a urgência das políticas públicas nesses três campos, considerados estratégicos para a preservação dos bens naturais e culturais, e sua respectiva manutenção.

A educação nesse campo deve iniciar-se pela percepção direta de que o patrimônio não se restringe somente aos bens culturais móveis e imóveis representativos da memória nacional, como monumentos, igrejas ou edifícios públicos. Pelo contrário, o conceito de patrimônio cultural é muito mais amplo, não se limita aos bens materiais ou às produções humanas, ele abrange o meio ambiente e a natureza, e ainda se faz presente em inúmeras formas de manifestações culturais intangíveis. A percepção da herança imaterial torna-se fundamental para a integração da população com suas próprias condições de existência, com a natureza e o meio ambiente. Essas relações constituem o espírito da cultura cidadã dos lugares e se manifesta por intermédio de cerimônias, linguagens do povo materializadas em atividades artesanais e produções artísticas ou literárias, canções, festas, receitas culinárias e saberes medicinais, entre outras manifestações sociais ou coletivas.

Desse modo, a educação patrimonial e ambiental torna-se tarefa prioritária, uma vez que consiste em revelar a diversidade e pontuar as mudanças culturais, sociais e ambientais que se processam com o passar dos tempos, sem desqualificar os conflitos de interesses dos distintos segmentos sociais. O ensino e a aprendizagem na esfera do patrimônio devem tratar a população como agentes histórico-sociais e como produtores de cultura. Para isso, devem ser valorizados os artesanatos locais, os costumes tradicionais, as expressões de linguagem 
regional, a gastronomia, as festas, os modos de viver e sentir das diversas etnias latinoamericanas. (PELEGRINI, 2006, p. 115-140)

Comer, portanto, não envolve apenas a natureza e a cultura. Situa-se entre estes dois aspectos e participa de ambas. As formas de alimentação podem dizer algo importante não apenas sobre as formas de vida, mas também sobre a estrutura de uma sociedade e sobre as regras que lhe permitem persistir e desafiar o tempo (Rossi, 2014).

O valor cultural também não está apenas nas coisas, mas é produzido no jogo concreto das relações sociais. Aquilo, por exemplo, que chamamos de bens culturais não tem em si sua própria identidade, mas a identidade que os grupos sociais lhe impõem. Assim, para falar de gastronomia, pode-se afirmar, por exemplo, que não existem valores universais e permanentes. Os objetos não têm, intrinsecamente, propriedades que não sejam físicoquímicas. As sociedades é que mobilizam tais e quais propriedades físico-químicas, sensorialmente perceptíveis, com produto e vetor de seus sentidos e valores. E esta mobilização é contingente, instável, mutável.

Conforme nos incita a pensar Menezes (1999), a história demonstra a oscilação do gosto e dos critérios de valorização e consumo. Dessa forma, os sistemas perceptivos são históricos, historicamente constituídos, operando historicamente e se transformando sem cessar. Os sentidos e valores não se confinam no universo mental. Para que tenham existência social, para que se traduzam em práticas, para que induzam a comportamentos, em síntese, para que se encarnem na materialidade da vida, eles precisam manifestar-se. Daí a relevância dos fenômenos sensoriais no campo da cultura. O chamado patrimônio cultural, portanto, para ser identificado e entendido, carece de conhecimento sobre os circuitos de produção e consumo de sentido e valor, numa sociedade.

Atualmente, dentro do município de Caldas Novas, poucos são os locais que ainda preservam e/ou se utilizam da culinária regional como referência para seus pratos. Pode-se citar como exemplo os "Doces Caseiros da D. Maria", reconhecido ponto de visitação turística que ainda preserva as tradições do feitio dos doces artesanais presentes na cultura goiana. Outro local também pertencente ao roteiro turístico é a "Cachaçaria Vale das Águas Quentes", que produz cachaças em alambiques de cobre, tal qual os fazendeiros da região faziam. Inclusive, esta empresa é pertencente a uma família de fundadores do município e representantes da população objeto de análise do presente trabalho, os Lopes de Morais.

De um modo geral, os restaurantes, lanchonetes e locais multiuso de alimentação tidos como "típicos" referenciam-se à culinária goiana ou "caseira" de modo generalizado. Não há uma referência específica a pratos, hortifrútis, carnes, temperos e preparos tipicamente locais. 
Parte pelas características globalizantes do turismo, parte pela maciça migração ocorrida a partir dos anos 1980, as famílias tradicionais remanescentes do município se "cosmopolizaram", se misturaram e absorveram estas características culturais e culinárias de outras regiões do país e do mundo, deixando de lado seus costumes culinários, reduzindo-os ao dia a dia das casas e de algumas festas familiares.

Convém neste particular atentar-se para o conceito de preservação ativa, desenvolvido por Pellegrini Filho (1993, p. 10):

\begin{abstract}
procuramos realçar a importância de se atentar para a preservação ativa, que conceituamos como: a conservação de bens naturais e culturais, dando-se-lhes ao mesmo tempo uma função conveniente, com soluções adequadas ao desejado progresso; portando, implicando o uso adequado de atrativos da natureza e da cultura porém evitando-se ou minimizando-se prejuízo a eles ou sua perda. Uma questão de desenvolvimento sustentado.
\end{abstract}

Nesse sentido, a preservação ativa do patrimônio cultural deve ser encarada como algo integrado ao quadro econômico-financeiro local, através de eventos culturais de caráter histórico/educacional não só voltado para uso efetivo da população local, mas também com o caráter turístico/informativo da população visitante. Assim assume-se aqui o interesse turístico, direta e indiretamente; ou seja, o aproveitamento turístico e de lazer acaba sendo uma decorrência natural em eventos desta monta. (Pellegrini Filho, 1993).

A gastronomia é local de afirmação da identidade. Comer é cultura, é um modo de socialização, de interação, de perpetuação. Nesse sentido, Roberto da Matta diferencia alimento e comida: “comida não é apenas uma substância alimentar, mas é também um modo, um estilo e um jeito de alimentar-se. E o jeito de comer define não só aquilo que é ingerido, como também aquele que o ingere" (1986, p. 56).

Desde a técnica de preparação dos alimentos ao uso de equipamentos e utensílios, a evolução do comer, cozinhar e servir representam hoje um dos mais importantes atributos da sociedade moderna, pois, apesar da evolução social obtida ao longo dos tempos, as necessidades de sobrevivência tendo como base as formas alimentares continuam (BARBOSA, 2008). A tradição ou cultura culinária sofrem e devem sofrer, ao longo da história, modificações. Mas estas são necessárias para que a própria cultura mantenha-se viva, ressignificando o lugar da tradição na atualidade, se justapondo, adequando-se aos novos padrões de produção e consumo, sem perder de vista a especificidade cultural dos lugares e saberes de uma dada sociedade.

\title{
3.1. Memórias, experiências e receitas: o patrimônio gastronômico de Caldas Novas
}


Uma das maiores influências de Caldas Novas na doçaria é a conhecida "Dona Maria", proprietária, junto com sua família, da fábrica e lojas de doces caseiros e licores que leva o seu nome. Dona Maria herdou dos pais a tradição que até hoje passa de geração para geração, e se reconhece como uma mulher conhecida até internacionalmente, e há mais de cinquenta anos acompanha de perto a fabricação dos doces e licores em geral.

Figura 1: D. Maria fabricando doce de leite

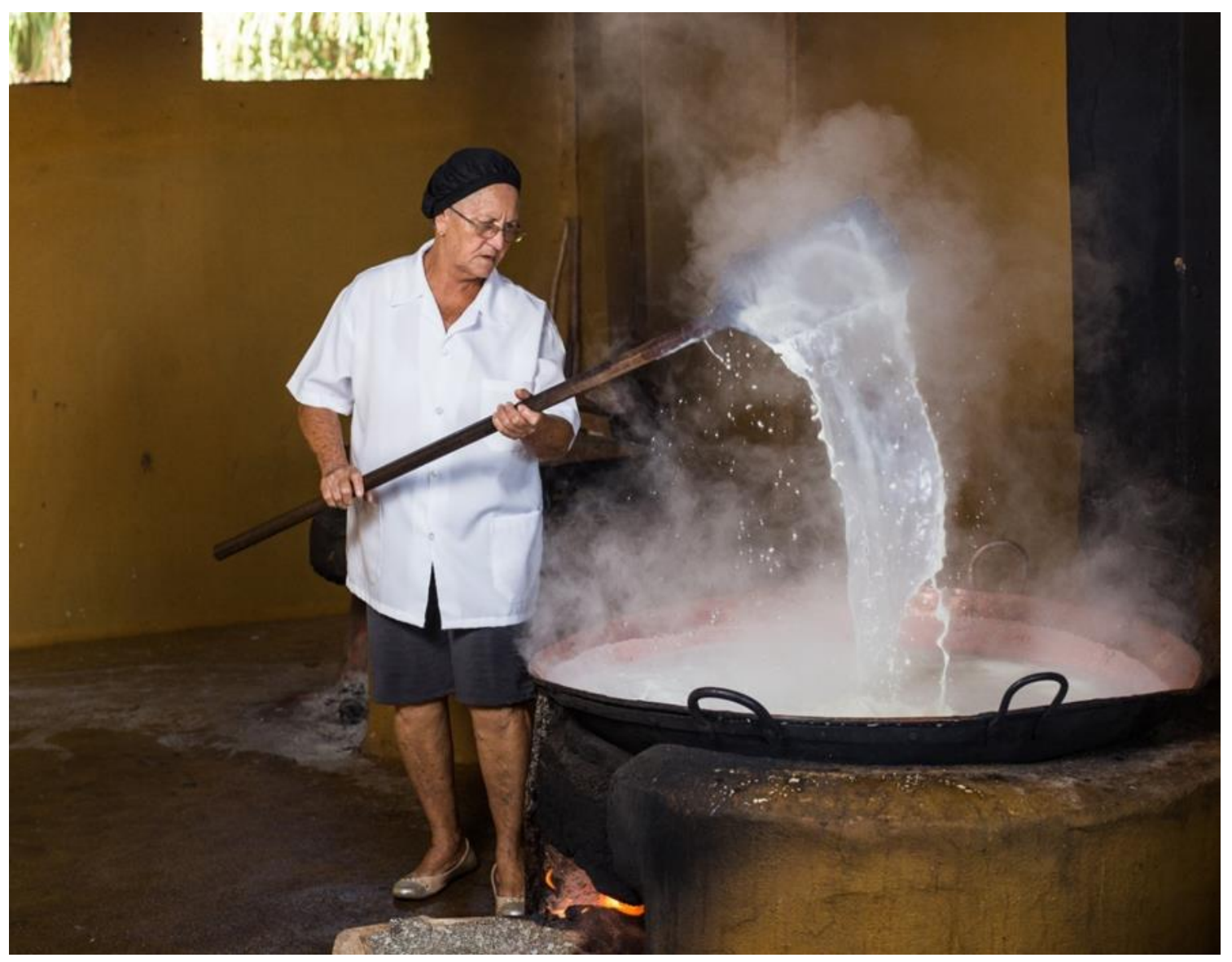

Fonte: fornecido pela colaboradora

Dona Maria narra que o primeiro doce feito em maior escala por sua mãe e repassado a ela como a grande receita e tradição familiar foi o doce de leite com pequi, que até hoje é um dos doces mais comercializados nas lojas. Já o licor tradicional e que representa não só sua família, mas a própria história gastronômica do município é o licor de mangaba, fruto típico do cerrado.

Conforme depreende-se deste relato, a doçaria tradicional da cidade de Caldas Novas, representada pela D. Maria, confunde-se com a tradição dos doces caseiros goianos de um modo geral. Sobressai no relato a afirmação da "invenção" do doce de leite com pequi e do licor de mangaba, atribuído pela D. Maria à sua mãe, Ilidia, sendo, portanto, pelo relato um 
produto típico da gastronomia caldas-novense. Nas pesquisas realizadas em Ortêncio (1980), realmente não há nenhuma referência a estas receitas, conferindo-se então um tom de veracidade ao relato descrito.

Dona Iraides de Melo Godoy (17/10/1920 - 25/02/2017) é representante de uma das mais tradicionais famílias de fundadores da cidade de Caldas Novas. Esposa de Celso de Godoy, filho do Cel. Bento de Godoy, era exímia cozinheira e fazia questão de executar todos os doces e quitutes dos grandes banquetes dados em razão dos casamentos, batizados e festas tradicionais em Caldas Novas.

Uma característica presente na culinária típica caldas-novense e que também foi absorvida por D. Iraides é a presença maciça da pimenta em todos os pratos. O caldasnovense típico é um exímio apreciador das pimentas, de todos os tipos e graus de ardência, sendo as preferidas as de maior grau de picância. Como curiosidade, mas também como exemplo da perspectiva aqui adotada, é pertinente citar Ortêncio (1980, pg. 61-62), que indica a presença de uma espécie de pimenta característica da região estudada e consumida pela população:

Pimentas [...] a bode com quatro tipos e denominações diferentes [...] e a puta-quepariu, amarela e bem maior. Esta última é originária da região de Caldas Novas e não é preciso ser curtida no óleo para que o incauto ou distraído grite o seu nome...

D. Elzita Santos Morais, hoje com 86 anos, é filha do Sr. Oscar Santos e de D. Irani Borges Santos. Oscar Santos é uma das figuras de maior destaque na consolidação e expansão do município de Caldas Novas, pela sua atuação política em várias esferas municipais e estaduais. Sempre foi uma grande entusiasta da culinária, sempre se dedicando ao feitio de vários pratos, com a grande admiração e apoio de seu marido, sr. Orcalino Lopes de Morais, que era filho de Ilídio Lopes de Morais e D. Joana.

Sr. Ilídio era "forte fazendeiro e comerciante" (GODOY, 1978, pg. 108) na cidade de Caldas Novas. Já D. Joana era filha do Cel. Orcalino dos Santos Veloso, natural de Araguari MG, comerciante e primeiro proprietário do que hoje convencionou-se chamar "Casarão dos Gonzaga", conforme cita Godoy (1978, pg. 107): "Como testemunho indelével do Cel. Orcalino, encontra-se, até hoje, erguido o sobrado que ele mesmo fizera construir para sua vivenda, atualmente de propriedade de João Gonzaga.”. Neste local o mesmo possuía um armazém e um pouso para tropeiros. D. Joana era irmã de D. Djanira, que se casou com o Dr. Ciro Palmerston Ribeiro Guimarães, e seus filhos (Martinho, Cyra, Nelson, Nilza, Omar e Terezinha) fundaram a Estância Pousada do Rio Quente, hoje Rio Quente Resorts (GODOY, 1978, pg. 107). 
Em 1970, quando tinha 39 anos, seu marido faleceu vítima de um infarto fulminante, o que num primeiro momento a afastou da cozinha. Depois, com o apoio da família e dos filhos, retomou a culinária, mas sem a mesma alegria de antes. D. Elzita corrobora as informações sobre as tradições culinárias caldas-novenses, conforme já citado anteriormente. A base é essencialmente mineira, tendo como matéria-prima básica as carnes de porco e galinha, feijão, arroz, milho e mandioca. $\mathrm{O}$ uso do pequi sempre foi comum, principalmente no preparo de pratos salgados. Pelo fato da colaboradora ter morado, ao longo da sua vida, em Goiânia e Brasília, além de Caldas Novas, introduziu nas suas receitas e no seu cardápio usos e costumes mais "cosmopolitas". Apesar desta tendência, as receitas mais tradicionais nunca deixaram de fazer parte do seu cardápio e de seus cadernos de receitas.

\section{Conclusões}

A recuperação desse patrimônio gastronômico faz-se urgente perante as vicissitudes de uma globalização que normatiza e iguala inclusive as relações culturais entre povos e países, em troca de uma homogeneização de gostos e paladares, hábitos e formas de consumo, como forma de atender a interesses capitalistas globais. Santos (2015) afirma que a instalação do capital "hegemônico" no território tem a capacidade de destruir as regras deste local em termos econômicos, sociais, políticos, culturais, morais ou geográficos. Especificamente em se falando da culinária e do hábito de comer, Cascudo (2011, pg. 23), afirma que "comemos não o substancial, mas o habitual, o lícito pela forma. Comemos, nós, os modernos citadinos, pela propaganda industrial irresistível”.

Equivale esta afirmação a dizer que a cultura, as tradições e costumes sucumbem à imperiosa necessidade da reprodução do capital, inclusive na vertente da culinária.

A resposta pode vir da apropriação da necessidade capitalista da reprodução do capital, observada também no turismo e na gastronomia, em uma perspectiva sustentável. O desafio é inverter o padrão de consumo desenfreado para um consumo consciente, valorizando a sazonalidade dos produtos e os pequenos produtores, sem deixar de lado o desafio de realizar o retorno econômico necessário à continuidade do destino turístico e da população nele inserida. Neste sentido, Santos (2015, pg. 114) afirma que:

Nisso, o papel do lugar é determinante. Ele não é apenas um quadro de vida, mas um espaço vivido, isto é, de experiência sempre renovada, o que permite, ao mesmo tempo, a reavaliação das heranças e a indagação sobre o presente e o futuro. A existência naquele espaço exerce um papel revelador sobre o mundo.

Além deste aspecto, a valorização da gastronomia em seu aspecto histórico e cultural permite que se atribua um valor econômico à história, tanto pela estranheza como pela 
novidade, ajudando também a perpetuar esta condição histórica, num ciclo constante de acumulação de riqueza econômica com preservação do patrimônio.

É nessa perspectiva que o trabalho de Müller (2012) propõe a construção de inventários gastronômicos em todas as regiões do país, formando um conjunto de conhecimentos que englobam as características tradicionais de produção ou coleta dos alimentos e os saberes sobre a elaboração dos mesmos na culinária tradicional em cada local. Esse trabalho, na visão da autora, pode ser feito pelos especialistas ou estudiosos da Gastronomia, contribuindo com seus conhecimentos específicos e unindo-os interdisciplinarmente com as demais áreas que podem contribuir com a elaboração de tais pesquisas.

\begin{abstract}
Como grande parte da Gastronomia Tradicional brasileira ainda não foi inventariada, entende-se como fundamental que as escolas de Gastronomia, que são as instituições diretamente ligadas ao assunto e responsáveis pela disseminação do conhecimento na área, comecem a fazer sua parte no que concerne à pesquisa para auxiliar na realização dos inventários gastronômicos, com o olhar do gastrólogo. Esse olhar especialista na construção de inventários da Gastronomia Tradicional possibilita a captação de detalhes que são fundamentais no processo produtivo, que abrangem questões pontuais como: a especificidade da matéria-prima os métodos de cocção e conservação, as reações químicas, as características organolépticas, formas de apresentação, entre outras questões de cunho interdisciplinar como o contexto cultural de criação, formas de consumo e as transformações ocorridas. (MÜLLER, 2012, p. 26)
\end{abstract}

A mesma autora, baseada em Fagliari (2005), propõe que a gastronomia local é também um elemento importante para a valorização do local turístico e fonte de recursos econômicos para as populações desses locais, unindo a preservação do patrimônio imaterial com o fortalecimento da economia.

\begin{abstract}
Ao servir-se dos produtos da culinária tradicional local, o turismo gastronômico pode funcionar como uma forma de conhecer novas culturas e hábitos alimentares, e pode constituir uma maneira de reapropriação de elementos culturais esquecidos, atuando na valorização cultural. (MÜLLER, 2012, p. 49)
\end{abstract}

Com esse seu trabalho, Müller oferece uma perspectiva de recuperação da culinária tradicional que contribui com a reflexão e atuação presentes em nossa proposta de pesquisa. As entrevistas realizadas e as receitas coletadas revelam a existência, de fato, de uma tradição gastronômica característica da cidade e região de Caldas Novas (GO). As entrevistas também evidenciam as diferentes perspectivas e possibilidades do aproveitamento das receitas tradicionais. No caso de D. Maria, a prática familiar e o espírito empreendedor possibilitaram a transformação do patrimônio gastronômico familiar e local em um empreendimento de sucesso no campo da gastronomia típica que está relacionada às atividades turísticas. 
A atividade de D. Maria e suas filhas contribuem para a preservação da culinária local, mais especificamente na produção de doces e licores, e também reforçam o entendimento dos autores que citamos neste trabalho, que enfocam o valor econômico e turístico das receitas características de uma localidade ou região.

Já as entrevistas com D. Yêda e D. Elzita, mostram que ainda existem meios para recuperar as tradições culinárias de Caldas Novas, à medida que os registros de receitas podem ser utilizados como veículo de disseminação desse conhecimento e de estímulo à produção desses pratos em um âmbito maior que o recesso familiar das entrevistadas.

Em Caldas Novas, conforme se procurou transmitir nesta reflexão, todo o trabalho de pesquisar, inventariar e valorizar socialmente, culturalmente e economicamente o patrimônio imaterial gastronômico local está por ser feito. A estratégia fundamental é que este artigo e outros trabalhos acadêmicos possam contribuir para que as atividades de conscientização e valorização desse patrimônio sejam estimuladas por meio da educação, por meio da divulgação das receitas e modos de fazer.

É possível, a partir dessa reflexão, mobilizar o poder público, as Universidades, os empreendedores da área turística e a população para um compromisso de valorização da cultura local, especialmente sua gastronomia tradicional, favorecendo as atividades turísticas e tornando as atividades turísticas em fatores de estimulação à preservação do patrimônio.

\section{Referências}

BARBOSA, Romero Ribeiro. Saberes, sabores e sentidos: a gastronomia no contexto da geografia cultural. In: ALMEIDA, Maria Geralda de; CHAVEIRO, Eguimar Felício; BRAGA, Helaine da Costa (orgs.). Geografia e Cultura: a vida dos lugares e os lugares da vida. Goiânia: Editora Vieira, 2008.

BRAUNE, Renata; FRANCO, Sílvia Cintra. O que é Gastronomia. São Paulo: Brasiliense, 2007.

BRASIL. Constituição da República Federativa do Brasil. Brasília, DF: Senado Federal: Centro Gráfico, 1988. 292p.

CASCUDO, Luís da Câmara. História da alimentação no Brasil. 4. ed. São Paulo: Global, 2011.

DA MATTA, Roberto. O que faz o Brasil, Brasil? Rio de Janeiro, Rocco. 1986.

DIAS, Reinaldo. Turismo e Patrimônio Cultural: recursos que acompanham o crescimento das cidades. São Paulo: Saraiva, 2006.

FAGLIARI, G. S. Turismo e Alimentação: Análises introdutórias. Ed.Roca, São Paulo, 2005.

FLANDRIN, J. L. MONTANARI, M. A história da alimentação. Paris. Ed. Fayard, 1996. 
GODOY, José Teóphilo de. História e Estórias de Caldas Novas. Goiânia: Oriente, 1978.

IBGE - Instituto Brasileiro de Geografia e Estatística- Cidades/Goiás/Caldas Novas. 2010. Disponível em < http://cod.ibge.gov.br/EIL> Acesso em abr 2017

IPHAN - Instituto de Patrimônio Histórico e Artístico Nacional. Cartas Patrimoniais. 2015. Disponível em: <http://portal.iphan.gov.br/portal/montarPaginaSecao.do?id=17575\&sigla=Institucional\&reto rno=paginaInstitucional $>$. Acesso em: 30/04/2017.

IPHAN. Termo de Referência para a Salvaguarda de bens Registrados como Patrimônio Cultural do Brasil. s.d. Disponível <http://portal.iphan.gov.br/portal/baixaFcdAnexo.do?id=1911> Acesso em: 30/04/2017

MACHADO, Jurema; BRAGA, Sylvia. Comunicação e Cidades Patrimônio Mundial no Brasil. Brasilia: UNESCO, IPHAN, 2010.

MENESES, Ulpiano T. Bezerra de. Os "usos culturais" da cultura. IN YÁZIGI, Eduardo; CARLOS, Ana Fani Alessandri; CRUZ, Rita de Cássia Ariza da (organizadores). Turismo: espaço, paisagem e cultura. 2. ed. São Paulo: Hucitec, 1999

MÜLLER, Silvana Graudenz. Patrimônio Cultural Gastronômico: identificação, sistematização e disseminação dos saberes e fazeres tradicionais. Florianópolis: Universidade Federal de Santa Catarina - Programa de Pós Graduação em Engenharia e Gestão do Conhecimento, 2012. Tese de Doutoramento. Disponível em: http://btd.egc.ufsc.br/wpcontent/uploads/2012/05/Silvana-Graudenz-M\%C3\%BCller.pdf Acesso em Abril 2017.

MÜLLER, Silvana Graudenz, AMARAL, Fabiana Mortimer e REMOR, Carlos Augusto. Alimentação e cultura: preservação da gastronomia tradicional. Anais do VI Seminário de Pesquisa em Turismo do Mercosul. Caxias do Sul, Julho 2010. Disponível em: http://www.ucs.br/ucs/tplVSeminTur\%20/eventos/seminarios_semintur/semin_tur_6/gt13/arq uivos/13/Alimentacao\%20e\%20Cultura\%20Preservacao\%20da\%20Gastronomia\%20Tradicio nal.pdf Acesso em Abril 2017.

OLIVEIRA, Hamilton Afonso de. Uma reflexão histórica do turismo: o caso Caldas Novas (1970-1990). Dissertação de mestrado apresentada à Faculdade de Ciências Humanas e Filosofia da Universidade Federal de Goiás. Goiânia, 2001

NARDIN, Caroline Rigo. Gostos, aromas e sabores: memórias e turismo gastronômico em Bento Gonçalves. Caxias do Sul: Universidade de Caxias do Sul, 2015. Dissertação de Mestrado.

ORTENCIO, Waldomiro Bariani. A Cozinha Goiana: estudo - receituário. $2^{\mathrm{a}}$ ed. Goiânia, Oriente, 1980.

PAULO, Renata Ferreira Calado de. O turismo e a dinâmica intra-urbana de Caldas Novas (GO): uma análise da expansão e reestruturação do complexo hoteleiro. Dissertação de mestrado apresentada ao programa de Pós-Graduação em Geografia da Universidade Federal de Uberlândia. Uberlândia, 2005. 
PELEGRINI, Sandra C. A. Cultura e natureza: os desafios das práticas preservacionistas na esfera do patrimônio cultural e ambiental. Revista Brasileira de História. São Paulo, v. 26, no 51, p. $115-140,2006$.

PELLEGRINI FILHO, Américo. Ecologia, cultura e turismo. Campinas, SP: Papirus, 1993.

ROSSI, Paolo. Comer: necessidade, desejo, obsessão. São Paulo: Editora Unesp, 2014.

SIQUEIRA, Michel Chelala. Caldas Novas 100 anos. Brasília: Academia Brasileira de Arte, Cultura e História; São Paulo: Instituto Biográfico do Brasil - IBB, 2012.

SCHLÜTER, Regina G. Gastronomia e Turismo. São Paulo, Aleph, 2003.

UNESCO. Recomendação para a salvaguarda do patrimônio cultural imaterial. Disponível em: $\quad<$ http://www.unesco.org.br/areas/cultura/areastematicas/patrimonio/ patrimonioimaterial/index_html/mostra_documento> Acesso em: 01/05/2017.

VARINE, Hugues de. As raízes do futuro: o patrimônio a serviço do desenvolvimento local. Trad. Maria de Lourdes Parreiras Horta. Porto Alegre: Medianiz, 2012 